\title{
Can media advocacy influence newspaper coverage of tobacco: measuring the effectiveness of the American stop smoking intervention study's (ASSIST) media advocacy strategies
}

\author{
Frances A Stillman, Kathleen A Cronin, W Douglas Evans, Alec Ulasevich
}

\begin{abstract}
Objective-To compare the rate and slant of local tobacco control print media coverage in ASSIST (American stop smoking intervention study) states as compared with non-ASSIST states.

Methods-Local tobacco control policy articles, editorials, and letters to the editors published from 1994 to 1998 clipped from all daily local newspapers in the USA were analysed $(n=95911)$. The main hypothesis tested for the existence of an interaction between ASSIST intervention and time. This interaction would represent a change in the difference between ASSIST and non-ASSIST states over the course of the intervention.
\end{abstract}

Results-No evidence of an ASSIST-year interaction was found. However, a main effect for ASSIST was significant for the percentage of articles with the model predicting higher rates of articles for ASSIST states. Similarly the rate of letters to the editor expressing protobacco control views was higher in ASSIST states than non-ASSIST states. No main effects or interactions were found for analyses of percentage of protobacco control editorials. Models controlled for a measure of preintervention tobacco control conditions at baseline.

Conclusions-The presence of an ASSIST main effect should be interpreted with caution because of the quasi-experimental design and the lack of information on article rates before the ASSIST intervention. Nonetheless, these preliminary findings suggest some possible effects of the media advocacy activities of ASSIST when controlling for differences in states' initial tobacco control conditions.

(Tobacco Control 2001;10:137-144)

Keywords: ASSIST; intervention study; media advocacy strategy

The American stop smoking intervention study (ASSIST) was initiated to reduce tobacco use primarily through policy based approaches to change the social-political environment. $^{1-3}$ In October 1991, 17 state health departments were awarded contracts by the National Cancer Institute (NCI) to develop and implement the ASSIST project. ${ }^{4}$ The states were given two years to plan the intervention, which began in 1993 and continued until 1999. The overall goal of ASSIST was to show that the application of statewide tobacco prevention and control programmes and policies would reduce cigarette consumption and smoking prevalence. NCI formed a partnership with the American Cancer Society to accomplish this goal. The ASSIST states developed coalitions to: (1) increase protobacco control media coverage, (2) strengthen tobacco control policies and laws, and (3) increase demand for smoking cessation services. ${ }^{12}$

A major effort of ASSIST was to use media advocacy strategies to increase news coverage of activities and to promote a comprehensive tobacco control agenda. Media advocacy has been used in many countries as an important approach to facilitating public debate by increasing the perceived relevance of an issue among the general public. ${ }^{5-7}$ The primary goal of media advocacy is to use the media to shape what, and how, people think about an issue and ultimately to encourage change through the regulatory or legislative actions of their communities. ${ }^{8-12}$ Each ASSIST site established a statewide media network of paid and volunteer media representatives from local communities. Specifically, ASSIST media network representatives were trained to do the following: (1) meet with newspaper editorial boards to promote positive coverage of tobacco control issues and to encourage favourable editorials on specific tobacco related issues; (2) encourage community members to contribute letters to the editor; (3) develop and maintain professional relationships with key reporters to foster coverage of tobacco as a public health problem; (4) develop effective use of both paid and public service advertising; and (5) understand the workings of newspapers and media outlets so they could more effectively communicate tobacco control messages.

In the present paper, we analysed the rate of print media coverage on local tobacco control issues to compare the amount of coverage in newspapers in ASSIST states with nonASSIST states. The non-randomised design of the ASSIST intervention, along with the lack of information on rates of tobacco related articles before the start of the ASSIST programme, make it difficult to draw inferences from observed differences between ASSIST and non-ASSIST states that were
21 May 200 5 January 2001 . Accepted 25 January 2001 
Table 1 Examples of tobacco policy issues tracked by the ASSIST media analysis system

\begin{tabular}{|c|c|c|c|c|}
\hline Clean indoor air & Access to minors & Economic disincentives & $\begin{array}{l}\text { Advertising and } \\
\text { promotions }\end{array}$ & Miscellaneous \\
\hline $\begin{array}{l}\text { - Smokefree bowling } \\
\text { alley } \\
\text { - Sports arena restricts } \\
\text { smoking } \\
\text { - Restricting smoking } \\
\text { in schools }\end{array}$ & $\begin{array}{l}\text { - Licensing vendors } \\
\text { - Youth buying } \\
\text { operations } \\
\text { - Banning vending } \\
\text { machines }\end{array}$ & $\begin{array}{l}\text { - Federal excise tax } \\
\text { - State excise tax }\end{array}$ & $\begin{array}{l}\text { - Banning billboards in } \\
\text { a state } \\
\text { - Removing billboards } \\
\text { from sports arenas } \\
\text { - FDA regulating } \\
\text { advertising of cigarettes }\end{array}$ & $\begin{array}{l}\text { - Cigarette package } \\
\text { labelling } \\
\text { - FDA regulating } \\
\text { nicotine content } \\
\text { - Lawsuits }\end{array}$ \\
\hline
\end{tabular}

FDA, Food and Drug Administration.

present throughout the time period analysed. ${ }^{3}$ Thus our main hypothesis focused on testing for a growing difference in frequency of all articles in the study between ASSIST and nonASSIST states over the period of the intervention (ASSIST ${ }^{\star}$ time interaction). Further exploratory analyses examined the same question with the data categorised by policy type (clean indoor air, youth access, economic disincentives, advertising and promotion, and miscellaneous). Secondary analyses were performed to investigate the percentage of published editorials and letters to the editor that contained a protobacco control slant.

\section{Methods}

ASSIST MEDIA TRACKING SYSTEM

Since 1 October 1993, articles, letters to the editor, editorials, and editorial cartoons about tobacco control policy issues from all daily newspapers in 50 states plus the District of Columbia have been obtained from a national clipping service using a specific search strategy. ${ }^{13}$ Newspapers that have primarily a national circulation, such as USA Today, the Wall Street fournal, and the Christian Science Monitor, were excluded from the search. Major newspapers such as the New York Times and the Washington Post were included in the search because even though they have a national circulation, they are primarily city newspapers with a section that covers only local news. Advertisements, movie reviews, restaurant reviews, syndicated columnists, and obituaries that had tobacco related content were excluded from the search.

Table 2 List of coded variables

\begin{tabular}{ll}
\hline Variable & Operational definition \\
\hline Date of publication & Day, month, and year of the publication of article \\
State & State in which the publication was primarily distributed \\
Name of publication & Name of the publication from which the article was obtained \\
Circulation & Number of copies of the publication distributed daily \\
Type of article & $\begin{array}{l}\text { News story (factual account of event or issue), editorial (non-factual } \\
\text { account/opinion of event or issue written by newspaper staff), or } \\
\text { letter to the editor (usually written to the newspaper by a member } \\
\text { of the community) }\end{array}$ \\
Policy type & $\begin{array}{l}\text { Clean indoor air, restricting access to minors, economic } \\
\text { disincentives (that is, excise taxes), advertising and promotions, and } \\
\text { a miscellaneous category (lawsuits, national settlement talks, } \\
\text { possible regulation of nicotine by the FDA) }\end{array}$ \\
Front page & $\begin{array}{l}\text { Prominence variable to identify the visibility of an article } \\
\text { Point of view (slant) }\end{array}$ \\
$\begin{array}{l}\text { Protobacco control (supportive of tobacco control) and } \\
\text { anti-tobacco control (supportive of tobacco industry) }\end{array}$ \\
$\begin{array}{l}\text { National or local in focus. Distinguishes source of story as a } \\
\text { national wire service (Associated Press, UPI, Reuters) or bylined by } \\
\text { local journalist }\end{array}$ \\
\hline
\end{tabular}

The database tracked over 1800 newspapers. The number varied slightly each year because of closures, mergers, and new startups. The average number of papers in ASSIST states (mean 37) did not significantly differ from number of newspapers in non-ASSIST states (mean 35). There was not much variability within each state over time, but states varied greatly in the number of newspapers published in each (from 7 to 112 newspapers in ASSIST states and from 2 to 143 in non-ASSIST states).

PRINT MEDIA SEARCH STRATEGY

A three tiered search strategy was developed to capture news and feature articles, letters to the editor, and editorials about tobacco control policies. The first tier consisted of tobacco keywords, the second tier of restriction/legislative keywords, and the third tier of policy related keywords. In an attempt to clip the most relevant articles, one word from each tier must have appeared in the article or headline in order for it to be clipped. Examples of the content of the policy related articles tracked by the system are depicted in table 1 .

DATA VARIABLES

The coding variables were developed before data collection. The complete list of variables in the ASSIST media tracking system is presented in table 2 . In this database, all hard news stories were coded as neutral in slant.

\section{CODING PROCEDURES}

All articles were clipped by a national service. Clips that met the search criteria were coded by one of three trained staff persons at the ASSIST coordinating centre and entered into the media tracking database. Monthly reliability checks were conducted. Inter-rater reliability for major coding categories (see above), evaluated with the $\kappa$ statistic, was extremely high, ranging between $0.95-0.99 \%$. Assessment of the database through random double data entry checks showed $0.95 \%$ agreement.

\section{SAMPLE OF ARTICLES}

The media tracking system began collecting data in October 1993; however, for the purposes of analyses presented here, we selected only articles from complete calendar years-1994, 1995, 1996, 1997, and 1998 - and only those that addressed local issues (that is, either municipal or state level), yielding a sample of 95911 articles. Because of a vendor's error, articles from small circulation newspapers (less than 50000 ) were not clipped by the service for three months from 
December 1995 to February 1996. Consequently, these data are missing from these analyses.

One of the main reasons for limiting our analyses to local stories was that ASSIST was designed as a grassroots intervention intended to affect local communities. It follows that ASSIST would be most effective in influencing the coverage of local initiatives. Furthermore, most newspapers in the ASSIST media tracking system are small and medium sized local dailies. As a rule, these types of newspapers would be more likely to cover local stories relying exclusively on wire services for national news coverage. ${ }^{14}$ Thus the national wire services and not the editorial interests or policies of the local papers may have a greater role in influencing the appearance of the national stories on tobacco control issues.

INITIAL OUTCOME INDEX (IOI)

One approach to remedy the lack of baseline data was to approximate baseline data by extracting tobacco control related articles from Lexus Nexus (L/N). A search on $\mathrm{L} / \mathrm{N}$ found that the "agenda setting" papers-New York Times, Washington Post, and Los Angeles Timespublished electronically from 1983. Altogether, 17 newspapers had electronic versions from 1990. In 1992, a year before data collection began, there were only 27 newspapers in the $\mathrm{L} / \mathrm{N}$ archive. Only five ASSIST states were represented by these dailies. We then considered whether the 17 newspapers that appear on L/N from 1990 are valid predictors for the entire database of newspapers by comparing the ratio of the number of articles that appear in the $17 \mathrm{~L} / \mathrm{N}$ papers to the total number of articles generated by our database each year. This comparison showed that the proportion of $\mathrm{L} / \mathrm{N}$ articles to the entire database fluctuates each year. Since these newspapers as a group appear to be unstable predictors of the number of articles in our database, this approach to establish a baseline was abandoned. Thus, we adopted the alternative approach of using an initial outcome index (IOI) to control for baseline differences.

An IOI was constructed to allow comparisons to be made across all states and the District of Columbia on the initial signs of progress associated with state comprehensive tobacco control programmes. The IOI uses data before the start of the ASSIST intervention and includes (1) cigarette price per pack, (2) smokefree workplace policies, and (3) smokefree home policies. The methodology for constructing IOI and a detailed report of the analyses conducted has been published. ${ }^{15}$ The index has been shown to be highly correlated with consumption and prevalence rates; states with higher IOI values have lower consumption and prevalence rates. For this study, the IOI is being used to control for possible differences in ability to deliver tobacco control interventions at baseline (1993).

Figure 1 presents histograms of IOI values for ASSIST states and non-ASSIST states. The histogram shows a difference between ASSIST and non-ASSIST states at baseline,
A ASSIST states

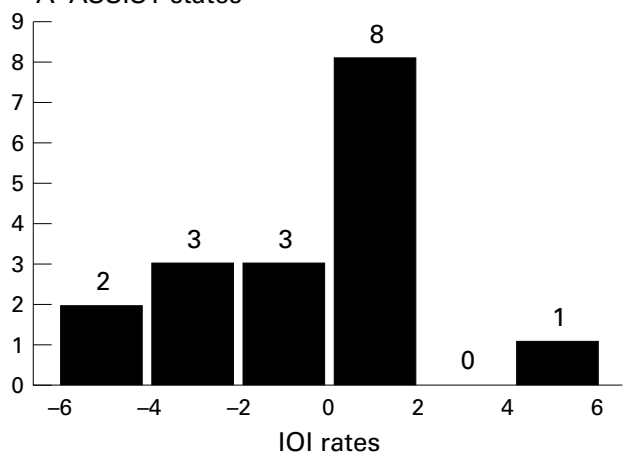

B Non-ASSIST states

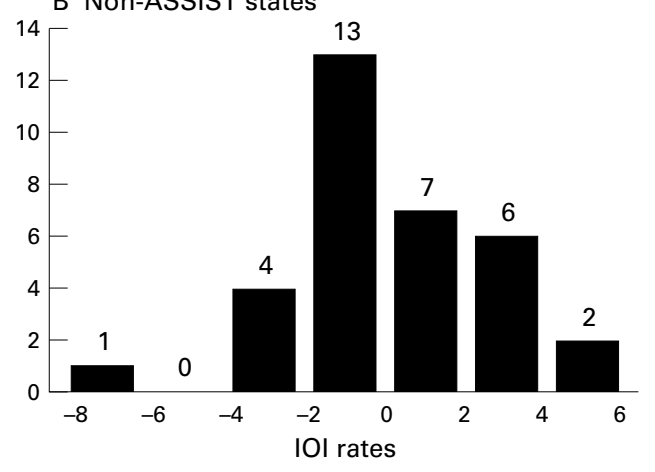

Figure 1 Initial outcome index (IOI) values for ASSIST states and non-ASSIST states.

with the distribution of IOI values lower in ASSIST states.

STATISTICAL ANALYSIS

A repeated measures analysis was performed to account for the presence of correlation between observations for the same state over time. The analysis uses the PROC mixed procedure in the statistical computer package SAS. ${ }^{16}$ PROC mixed is used for mixed linear regression equations. Mixed models are more general than standard linear regression models in that they allow for the modelling of the variances and covariance of the observations as well as the means. In this application we model the covariance structure to account for correlations between repeated observations taken over time on the same state. A transformation of the dependent variable-average article rate for each state-was used to normalise the error terms. We found that a natural log transformation with an offset of 0.05 normalised errors for all articles combined and when categorised by policy type. Therefore the model was fit using the dependent variable $\ln$ (average rate +0.05 ). Tests for significance of independent variables are based on partial sums of squares $\mathrm{F}$ tests. ${ }^{17}$ Least squares adjusted means are presented for descriptive purposes. ASSIST status and calendar year were included in the model as categorical variables, and the IOI rate was included as a continuous variable. Correlation within a state over time was modelled using several different structures on the covariance matrix. An autoregressive of order one (AR(1)) structure, with the AR(1) parameter estimated separately for the ASSIST and non-ASSIST states, was found to fit the data 
Table 3 Mean (SD) of average yearly rates of articles published in ASSIST and non-ASSIST states *

\begin{tabular}{|c|c|c|c|c|c|}
\hline & 1994 & 1995 & 1996 & 1997 & 1998 \\
\hline \multicolumn{6}{|l|}{ Overall } \\
\hline ASSIST states & $18.31(9.43)$ & $10.80(7.81)$ & $10.95(8.02)$ & $14.73(9.74)$ & $13.78(7.11)$ \\
\hline Non-ASSIST states & $12.13(8.05)$ & $7.64(5.57)$ & $7.31(4.91)$ & $11.10(9.25)$ & $10.25(9.16)$ \\
\hline \multicolumn{6}{|l|}{ Clean indoor air } \\
\hline ASSIST states & $10.76(5.71)$ & $5.00(4.65)$ & $2.99(2.18)$ & $3.37(2.17)$ & $3.97(3.50)$ \\
\hline Non-ASSIST states & $7.30(4.71)$ & $3.81(3.64)$ & $1.91(1.92)$ & $1.95(1.57)$ & $2.06(2.32)$ \\
\hline \multicolumn{6}{|l|}{ Youth access } \\
\hline ASSIST states & $1.88(2.14)$ & $3.63(3.93)$ & $3.48(2.68)$ & $3.62(2.30)$ & $1.74(1.05)$ \\
\hline Non-ASSIST states & $0.84(0.82)$ & $2.16(2.11)$ & $2.00(1.99)$ & $2.46(1.75)$ & $1.27(1.18)$ \\
\hline \multicolumn{6}{|l|}{ Economic disincentives } \\
\hline ASSIST states & $3.01(2.75)$ & $0.73(1.05)$ & $1.47(2.89)$ & $2.39(5.97)$ & $1.31(0.75)$ \\
\hline Non-ASSIST states & $2.10(2.98)$ & $0.60(0.76)$ & $1.16(2.27)$ & $2.60(6.07)$ & $1.92(4.03)$ \\
\hline \multicolumn{6}{|c|}{ Advertising and promotion } \\
\hline ASSIST states & $0.92(0.53)$ & $0.74(0.39)$ & $0.63(0.46)$ & $1.00(0.77)$ & $0.71(0.62)$ \\
\hline Non-ASSIST states & $0.65(0.52)$ & $0.53(0.46)$ & $0.30(0.27)$ & $0.57(0.65)$ & $0.49(0.59)$ \\
\hline \multicolumn{6}{|l|}{ Miscellaneous } \\
\hline ASSIST states & $1.73(0.92)$ & $1.80(1.24)$ & $2.86(1.87)$ & $4.36(2.55)$ & $6.04(3.81)$ \\
\hline Non-ASSIST states & $1.24(1.25)$ & $1.29(1.18)$ & $2.21(2.16)$ & $3.52(3.55)$ & $4.51(3.68)$ \\
\hline
\end{tabular}

*Washinton DC was excluded because of the rates in that district being an outlier.

best based on model fit criteria computed by the mixed procedure. The $\mathrm{AR}(1)$ structure specifies that the correlation between measurements from the same state were larger when the measurements were close together in time than when the measurements were further apart in time.

Secondary analyses were performed on the percentages of protobacco control editorials and letters to the editor (that is, number of items expressing protobacco control position over the total number of items). The reason behind separating editorials and letters to the editor is that editorial policy drives editorials, while some interest in balanced presentation and random chance of who submits a letter drives letters to the editor.

When analysing the percentage of editorials and letters to the editor that have a protobacco control slant, we assume that the data follows a binomial distribution and use a logistic regression approach. The macro GLIMMIX available with the SAS computer package was used to perform the analysis. ${ }^{17}$ Similar to PROC mixed, GLIMMIX allows for the modelling of the covariance structure in fitting generalised linear models. As in the analysis on the total number of articles, an $\mathrm{AR}(1)$ structure is used to model the correlation between measurements from the same state.

\section{Results}

RATE OF ARTICLES

The rate of articles was significantly higher in ASSIST than non-ASSIST states, but there was no evidence of ASSIST-year interaction. The average rate per year was calculated for each state by dividing the total number of articles published in that year by the number of active newspapers for that state. The data were aggregated to years to stabilise the rates. Table 3 shows means and standard deviations (SD) of the average rates for ASSIST and non-ASSIST states for all articles and categorised by policy.

Regression coefficients for all articles and for articles categorised by policy type are shown in table 4 . The regression coefficients estimate the effect of ASSIST status, year, IOI rate, and the ASSIST-year interaction on the transformed dependent variable, ln (average rate + 0.05). The results indicate that there was no evidence of an ASSIST-year interaction in the primary model using all articles in the study or when categorised by policy type. This suggests that the difference in rates between ASSIST and non-ASSIST states remained constant over time. IOI scores were significant in all cases, with higher IOI scores predicting higher rates of articles. Calendar year was also a significant variable in each of the models and

Table $4^{*}$ Parameter estimatest (SE) from regression of rates for all articles and categorised by policy type

\begin{tabular}{|c|c|c|c|c|c|c|}
\hline & Overall & Clean indoor air & Youth access & $\begin{array}{l}\text { Economic } \\
\text { disincentives }\end{array}$ & $\begin{array}{l}\text { Advertising and } \\
\text { promotion }\end{array}$ & Miscellaneous \\
\hline Intercept & $2.55(0.12)$ & $1.15(0.15)$ & $0.45(0.18)$ & $0.19(0.23)$ & $-0.51(0.16)$ & $1.64(0.15)$ \\
\hline ASSIST-No $\neq 0$ & $-0.53(0.18)$ & $-0.78(0.20)$ & $-0.50(0.23)$ & $-0.13(0.31)$ & $-0.63(0.22)$ & $-0.49(0.23)$ \\
\hline $\begin{array}{l}\text { Yearł } \\
1994\end{array}$ & $0.29(0.15)$ & $1.16(0.18)$ & $-0.26(0.23)$ & $0.67(0.32)$ & $0.36(0.21)$ & $-1.15(0.17)$ \\
\hline 1995 & $-0.35(0.13)$ & $0.20(0.17)$ & $0.46(0.21)$ & $-0.94(0.31)$ & $0.15(0.20)$ & $-1.20(0.16)$ \\
\hline 1996 & $-0.32(0.12)$ & $-0.20(0.15)$ & $0.54(0.19)$ & $-0.82(0.30)$ & $-0.08(0.18)$ & $-0.75(0.13)$ \\
\hline 1997 & $0.02(0.09)$ & $-0.03(0.12)$ & $0.69(0.15)$ & $-0.15(0.26)$ & $0.38(0.14)$ & $-0.30(0.10)$ \\
\hline IOI Score‡ & $0.11(0.03)$ & $0.09(0.03)$ & $0.11(0.03)$ & $0.12(0.04)$ & $0.13(0.03)$ & $0.09(0.04)$ \\
\hline \multicolumn{7}{|l|}{ ASSIST-year inte } \\
\hline $\mathrm{No}^{\star} 1994$ & $-0.01(0.22)$ & $0.29(0.25)$ & $-0.17(0.30)$ & $-0.58(0.42)$ & $0.14(0.30)$ & $-0.25(0.28)$ \\
\hline $\mathrm{No}^{\star} 1995$ & $0.10(0.20)$ & $0.44(0.24)$ & $0.02(0.28)$ & $-0.16(0.41)$ & $0.11(0.29)$ & $-0.01(0.26)$ \\
\hline $\mathrm{No}^{\star} 1996$ & $0.01(0.18)$ & $0.18(0.21)$ & $-0.16(0.25)$ & $-0.22(0.39)$ & $-0.18(0.27)$ & $-0.07(0.23)$ \\
\hline $\mathrm{No}^{\star} 1997$ & $0.00(0.14)$ & $0.02(0.17)$ & $0.01(0.20)$ & $-0.44(0.32)$ & $-0.27(0.22)$ & $-0.08(0.17)$ \\
\hline
\end{tabular}

*Washinton DC was excluded because of the rates in that district being an outlier.

†Parameter estimates and standard errors are for the transformed dependent variable $\ln$ (average rate +0.05 ).

$\neq$ Significant with $\mathrm{p}<0.05$ for all articles and articles categorised by policy type; degrees of freedom for $\mathrm{F}$ test are 1 and 47 for ASSIST and IOI score, and 4 and 192 for year and ASSIST-year interaction.

§ASSIST states include Colorado, Indiana, Massachusetts, Maine, Michigan, Minnesota, Missouri, North Carolina, New Jersey, New Mexico, New York, Rhode Island, South Carolina, Virginia, Washington, Wisconsin, and West Virginia. 

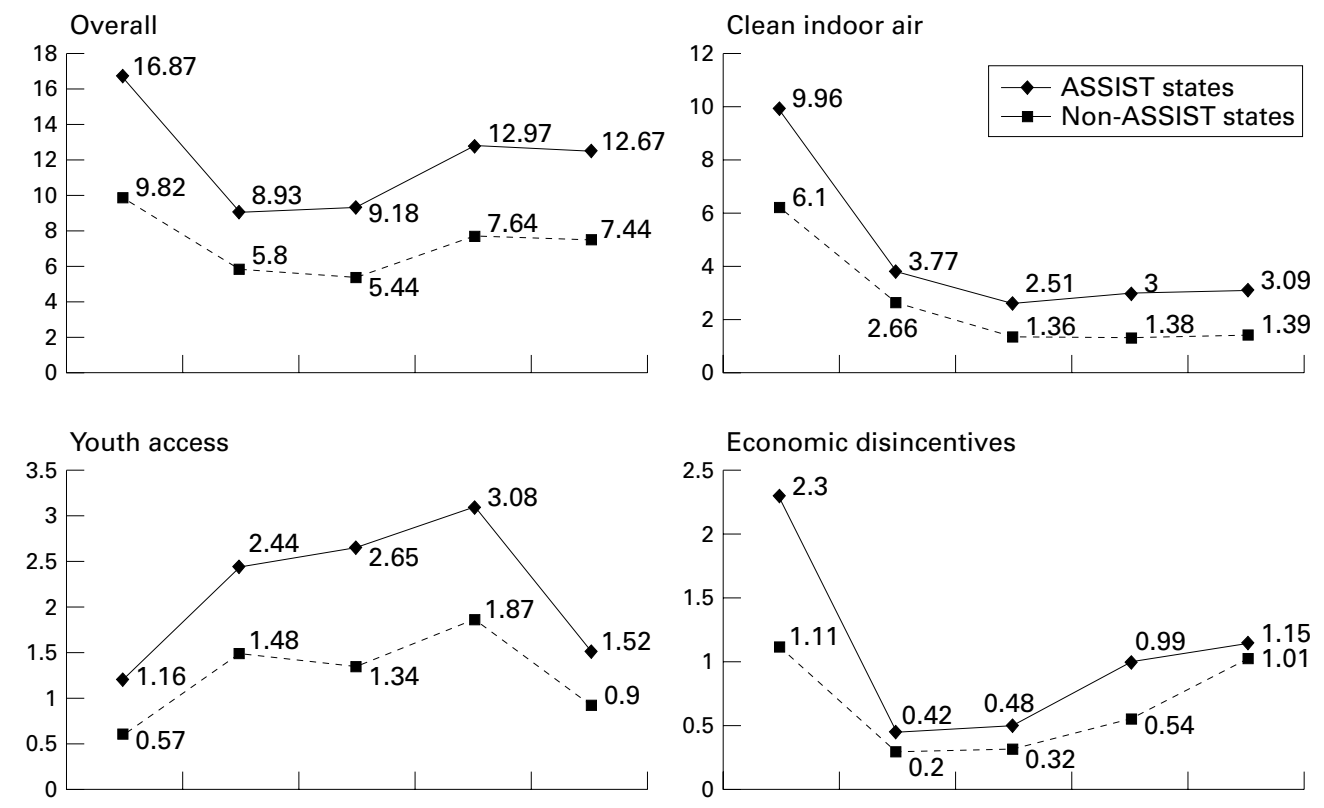

Economic disincentives
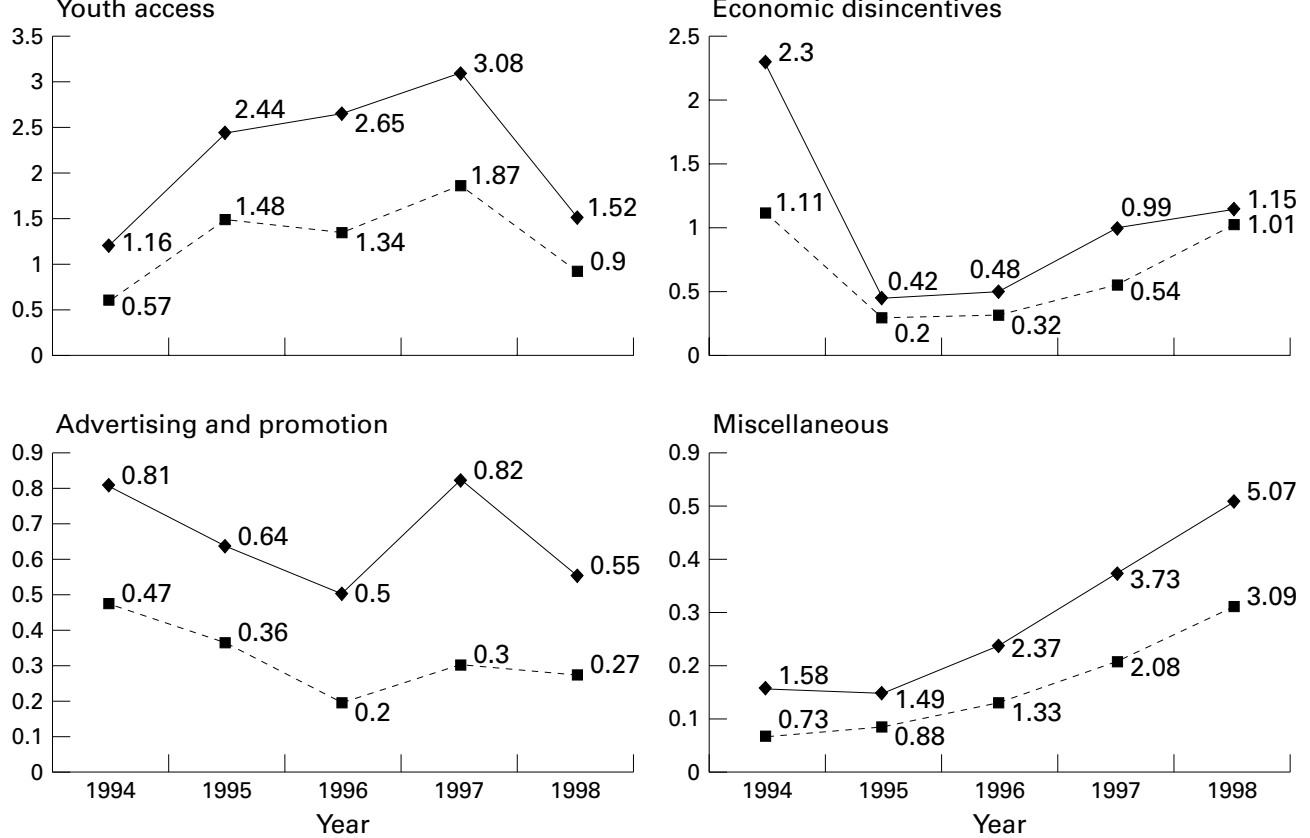

Figure 2 Modelled means of articles published in ASSIST and non-ASSIST states overall and by policy category adjusted for IOI score.

allowed for the modelling of the peaks and valleys of coverage observed in both ASSIST and non-ASSIST states. Figure 2 plots the marginal means for ASSIST and non-ASSIST states by calendar year adjusted for IOI scores for all articles and by policy type based on the fitted models.

The main effect for ASSIST was further explored by reanalysing the data without the ASSIST-year interaction term. ASSIST remained a significant variable for all articles and for articles categorised by policy type, with the models predicting higher rates of articles for ASSIST states. The mean rates adjusted for IOI scores and calendar year and 95\% confidence interval (CI) for all articles were 7.02 (95\% CI 5.82 to 8.47 ) for non-ASSIST states and 11.86 (95\% CI 9.76 to 14.40 ) for ASSIST states. Similar analyses were performed by policy type: estimates were 2.11 (95\% CI 1.77 to 2.51 ) for non-ASSIST states and 3.92 (95\% CI 3.10 to 4.94$)$ for ASSIST states for clean indoor air; 1.13 (95\% CI 0.93 to 1.39$)$ for non-ASSIST states and $2.05(95 \%$ CI 1.55 to 2.72) for ASSIST states for youth access; 0.57 (95\% CI 0.42 to 0.78$)$ for non-ASSIST states and 0.89 (95\% CI 0.67 to 1.17) for ASSIST states for economic disincentives; 0.32 (95\% CI 0.25 to 0.39 ) for non-ASSIST states and 0.64 (95\% CI 0.50 to
0.81) for ASSIST states for advertising and promotion; 1.40 (95\% CI 1.06 to 1.83 ) for non-ASSIST states and 2.56 (95\% CI 2.01 to 3.26) for ASSIST states for miscellaneous. Note that the model predicts higher means for ASSIST states for economic disincentives even though the mean rates for ASSIST and non-ASSIST states appear similar in table 4 . This can be explained by the IOI score being lower in ASSIST states and the association between lower scores for the IOI and lower expected rates of articles. In other words, nonASSIST states had a more favourable preintervention tobacco control environment as measured by the IOI.

Preliminary analyses also included an IOI score-ASSIST interaction. This interaction was found not to be significant for all articles or articles categorised by policy type and, therefore, was excluded from the model.

SLANT

Overall, between 1994 and 1998 there were 17574 editorials captured by the ASSIST media tracking system. For ASSIST states, the mean (SD) rate of protobacco control editorials for 1994 was 60 (15)\%. In 1995 and 1996, the rates were somewhat higher at $66(14) \%$ and $67(12) \%$, respectively. The rate increased slightly in 1997 to 69 (10)\%, and decreased 
slightly in 1998 to 66 (11)\%. For non-ASSIST states, the rate for 1994 was $64(14) \%$, and for 1995 it was 70 (14)\%; for 1996 and 1997 the rates were identical (69 (17)\% for 1996 and 69 (12)\% for 1997). In 1998, the rate of protobacco control editorials among nonASSIST states was 65 (12)\%.

During the same period, there were 15141 letters to the editor. For ASSIST states, the rate of letters to the editor with protobacco control slant in 1994 was 53 (11)\%. In 1995 and 1996 the rate was higher-66 (13)\% and 66 (11)\%, respectively. In 1997, the rate of protobacco control letters to the editor was 61 (8)\% and it dropped to $53(10) \%$ in 1998. Among states not participating in ASSIST, in 1994 the rate of protobacco control letters to the editor was $49(11) \%$. The protobacco control slant rose to $64(18) \%$ in 1995 and remained the majority opinion expressed in the letters to the editor in 1996 (63 (19)\%) and 1997 (59 (19)\%). In 1998, the rate of protobacco control letters to the editor dipped below $50 \%$ (48 (14)\%).

When modelling the percentage of editorials that had a protobacco control slant, the ASSIST main effect and ASSIST-year interaction were not significant for all policies combined. The IOI rate was borderline significant $(p=0.08)$. Year was the only significant variable in the analysis. Without the ASSISTyear interaction term in the model, the mean proportion of editorials with a protobacco control slant adjusted for the IOI rate and calendar year were 0.66 (95\% CI 0.64 to 0.68 ) for nonASSIST states and 0.67 (95\% CI 0.64 to 0.70 ) for ASSIST states. Thus, this analysis did not show differences between ASSIST and non-ASSIST states. Analyses by policy type may not have been conclusive because of the smaller number of editorials.

The analysis of percentages of letters to the editor that had protobacco control slant revealed significant main effects for ASSIST $(p=0.004)$, year of publication $(p=0.0003)$, and IOI $(p=0.0003)$. However, the interaction between ASSIST and year was not significant. Of interest here is the comparison between ASSIST and non-ASSIST states. Adjusted for IOI, the mean for ASSIST states $(0.59,95 \%$ CI 0.57 to 0.62$)$ was significantly greater than the mean for non-ASSIST states $(0.54,95 \%$ CI 0.52 to 0.56$)$.

\section{Discussion}

Evaluating effectiveness of media advocacy efforts is not a simple endeavour. In particular, the media's coverage of any issue, such as tobacco, is complex in nature and the overall variations in article quantity are greatly influenced by the presence of significant events, legislation, or other external factors in the national, regional, and local discourse about tobacco. ${ }^{18}{ }^{19}$ In this context, we were able to demonstrate several important findings about the effectiveness of media advocacy and ASSIST: the presence of an ASSIST effect, suggesting media advocacy efforts may have increased the coverage of tobacco control issues; ASSIST policy effects, indicating greater coverage of policy issues in ASSIST states; and an effect for slant for letters to the editor, indicating more protobacco control coverage in ASSIST states. However, the main hypothesis that the rate of local tobacco control articles in ASSIST states would increase over time as compared to non-ASSIST states during the intervention was not confirmed. Presently, we do not have data to address why this interaction was not found. However, we can suggest some possible explanations.

One explanation for why we did not find increasing differences in the amount of coverage is the episodic nature of the media's coverage of any issue as predicted by agenda setting theory. ${ }^{20}$ The observed trends in ASSIST media data reflect distinct peaks and valleys, overall and by specific tobacco control policy types, rather than a linear increase in media coverage over time. ${ }^{21}$ Such periodic coverage of the issues might have made impossible a continuous improvement in the effectiveness of media advocacy efforts or it may be difficult to actually assess progress since rate of coverage depends highly on so many external factors. Furthermore, the assumption that newspapers are willing to allocate only a certain amount of print space to tobacco control issues (the so-called "news hole" or amount of available space editors are willing to devote to a topic such as tobacco) $)^{22}$ might have created a ceiling effect countering the postulated effects of improved media advocacy skills gained by ASSIST personnel during the intervention period.

Similar explanations would apply to why we did not find an ASSIST by year interaction for rate of letters to the editor expressing protobacco control position. Here, the episodic nature of coverage of tobacco control issues would be confounded with public sentiment about a particular issue. For instance, the public showed considerable ambivalence toward the Master Settlement Agreement, ${ }^{23}$ the topic that newspapers covered extensively toward end of the data collection period reported here. Thus, the emergence of different issues might have affected the ability of ASSIST staff to rally interest or support among the public at different times.

We were not able to demonstrate any difference on the slant of editorials (protobacco control or antitobacco control) between ASSIST states and non-ASSIST states. It appears that the slant of editorial coverage of tobacco control did not change over time and was not different between ASSIST and non-ASSIST states. There are several plausible explanations. First of all, it might have been more difficult to influence the slant of editorials than to advocate coverage of tobacco control issues. Second, since hard news stories were coded as having a neutral slant by default, slant was actually coded for only a small subset of data. Considering that, in general, the opinions expressed in editorials were supportive of a protobacco control position, ${ }^{13}$ there might have been too little variability between ASSIST and non-ASSIST states to detect a significant difference. Analysis of slant of print media, 
especially the subtle biases in coverage of hard news stories favouring one position or another, requires a more in-depth analysis that goes beyond the scope of the ASSIST media tracking system.

Since we were unable to obtain baseline data on print media coverage, the $\mathrm{IOI}^{15}$ was used to control for the possibility of more favourable preintervention tobacco control conditions in the ASSIST states that might bias the sample. The IOI was identified as a possible control because it is a composite measure of state tobacco control conditions as conceptualised for the ASSIST evaluation. ${ }^{3}$ Moreover, our analysis found that the IOI was positively associated with higher overall rates of articles, suggesting that IOI controlled for some baseline difference related to publication rates. ASSIST states were found to have a lower composite IOI score than non-ASSIST states at baseline. Based on the lower IOI, the natural hypothesis would be that in the absence of an ASSIST effect, ASSIST states would produce a lower rate of articles than non-ASSIST states. The opposite result was observed.

The analysis showed a main effect for ASSIST, indicating that the overall rate of local articles in ASSIST states was greater than in non-ASSIST states. Thus while ASSIST did not produce an increasing rate of media coverage over time, the intervention states generally demonstrated greater overall local coverage of tobacco control. Given the quasi-experimental design and the lack of information on article rates before the ASSIST intervention, we must be cautious in attributing these effects to the intervention. However, given the IOI score as a control for possible baseline differences between the ASSIST and non-ASSIST states, we propose that ASSIST media advocacy activities are a possible explanation for the observed differences in rate of local articles.

ASSIST states showed a higher overall rate of coverage not only on all tobacco control topics, but also by specific policy types, including clean indoor air, youth access, economic disincentives, and advertising restrictions. This suggests that media advocacy on specific tobacco control issues may influence amount of print media coverage of those issues, which was one of the major strategies used in the ASSIST intervention.

We must exercise similar caution when interpreting the significant difference between ASSIST and non-ASSIST states in the percentage of letters to the editor expressing protobacco control positions. One explanation for this finding is that it may indicate effectiveness of media advocacy activities in ASSIST states that included letter writing campaigns. A number of other factors also could have contributed to these results, such as a more favourable coverage of tobacco control activities and greater willingness of newspapers to publish protobacco control letters to the editor. However, we have no data to support these conclusions.

A possible limitation to generalisation of our findings is that we focused exclusively on print media. Yet, the coverage of health related
What is already known on this subject

Media advocacy is an effective tool to bring public health issues to the attention of the public. Major tobacco initiatives in the USA and internationally have incorporated media advocacy as a primary tactic to engender public support for tobacco control policy issues. Measuring the effectiveness of media advocacy interventions is not as straightforward as evaluating other types of health promotion or tobacco control efforts because of the episodic and cyclic nature of media coverage on any given topic. Different states as well as countries have varying levels of ability to deliver tobacco control efforts and use different strategies to achieve results. The American stop smoking intervention study (ASSIST), the largest US federally funded tobacco control programme, used media advocacy as one of its primary intervention strategies from 1993 to 1999.

\section{What this paper adds}

This study showed that the amount of tobacco coverage in newspapers was greater in ASSIST states than in non-ASSIST states when controlling for differences in states' initial commitment to tobacco control. Since ASSIST states had lower baseline scores on this initial commitment to tobacco control, it was predicted that fewer articles would be found. Just the opposite was observed, suggesting that focusing on media advocacy may have influenced the amount of coverage. Media advocacy can engender public support and increase the level of understanding for tobacco control issues. Media advocacy needs to be considered as an important tool in the efforts to curb the tobacco pandemic.

issues by electronic media does not appear to be different in terms of content coverage, and one may argue that television coverage is derivative of print media coverage. ${ }^{24}$ In other words, television is more likely to cover stories appearing in print than other way around.

This initial exploratory analysis of differences in the frequency of media coverage between ASSIST and non-ASSIST states is suggestive, but not conclusive, and highlights the need for additional research. The ASSIST evaluation is ongoing, and these results should be treated cautiously until the full model being developed by NCI is complete. ${ }^{3}$ Other factors, such as resources for tobacco control efforts and the influence of the tobacco industry, are being explored to understand their effect on tobacco control outcomes, such as media rates and changes in prevalence and consumption rates. These preliminary findings suggest some possible effects of the media advocacy activities of ASSIST when controlling for differences in states' initial ability to deliver tobacco control interventions at baseline. The differences found between newspaper coverage of tobacco control may be attributable to ASSIST media advocacy 
efforts. Thus it is valuable to investigate the effectiveness of ASSIST media advocacy in promoting media coverage, and the effect of coverage on "downstream" outcomes such as public attitudes, opinions, and behaviour related to tobacco use and the tobacco industry.

1 Manley MS, Lynn W, Epps RP, et al. The American stop smoking intervention study for cancer prevention: an overview. Tobacco Control 1998;6(suppl 2):S5-11.

2 Shopland DR. Smoking control in the 1990s: A National Cancer Institute model for change. Am f Public Health 1993;83:1208-11.

3 Stillman FA, Hartman A, Graubard B, et al. The American stop smoking intervention study (ASSIST): conceptual framework and evaluation design. Evaluation Review 1999 23:259-80.

4 Hall NG, Hershey JC ,Kessler LG, et al. A model for making project funding decisions at the National Cancer Instiing project funding decisions at
tute. Oper Res 1992;40:1040-52.

5 Chapman S, Lupton D. The fight for public health: principtes and practice of media adhe fight for public health. principles

6 Puska P, Wiio J, McAlister A, et al. Planned use of mass media in national health promotion: the "Keys to Health" media in national health promotion: the "Keys to Health"
TV program in 1982 in Finland. Can $\mathcal{F}$ Public Health 1985; TV program in

7 Wallack L. Social marketing and media advocacy: two approaches to health promotion. World Health Forum 1990;11:143-54.

8 Holder HD, Treno AJ. Media advocacy in community prevention-news as a means to advance policy change. Addiction 1997;92(suppl 2):S189-99.

9 Chapman S. The news on smoking: newspaper coverage of smoking and health in Australia, 1987-88. Aust f Public Health 1989;79:1419-21.

10 Schooler C, Sundar S, Flora J. Effects of the Stanford fivecity project media advocacy program. Health Educ $Q$ 1996;23:346-64.
11 Wallack L, Dorfman L, Jernigan D, et al. Media advocacy and public health: power for prevention. Newbury Park, California: Sage, 1993.

12 Baillie RK. Determining the effects of media portrayals of alcohol: going beyond short term influence. Alcohol Alcohol 1996;31:235-42.

13 Stillman FA, Evans WD, Ulasevich A. Media coverage of the master settlement agreement: lessons to be learned. American Public Health Association, 1999 [abstract]. http://alpha.confex.com/apha/128am/techprogram paper_10148.htm

14 Shaw EJ. Newspaper reading in small towns. ANPA News Research Report No 12, 1978;29-34.

15 Gilpin EA, Stillman FA, Hartman AM. Index for state tobacco control initial outcomes. Am $\mathcal{f}$ Epidemiol 2000; 152:727-38.

16 SAS Institute Inc. SAS/STAT User's Guide, Version 6, Fourth Edition, Volume 1. Cary, North Carolina: SAS Institute Inc, 1989:120-22

17 Littell RC, Milliken GA, Stroup WW, et al. SAS system for mixed models. Cary, North Carolina: SAS Institute Inc, 1996:87-134

18 Iyengar S. Is anyone responsible? How television frames political issues. Chicago: University of Chicago Press, 1991.

19 McCombs M, Shaw D. The agenda setting function of mass media. Public Opinion Quarterly 1973;36:176-87.

20 Downs A. Up and down with ecology: the issue attention cycle. The Public Interest 1972;28:38-50.

21 Cronin K, Stillman FA, Evans WD, et al. Between states comparisons using a media tracking system: an illustration. parisons using a media tracking system: an illustration.
American Public Health Association, 1999 [abstract]. http://alpha.confex.com/apha/128am/techprogram/ http://alpha.confex.co

$22 \mathrm{Zhu}$, J. Issue competition and attention distraction in agenda setting. A zero-sum perspective. Fournalism Quarterly 1992;69:825-36.

23 Blendon RJ, Young JT. The public and the comprehensive tobacco bill. $7 A M A$ 1998;280:1279-84.

24 Moynihan R, Bero L, Ross-Degnan D, et al. Coverage by the news media of the benefits and risks of medication. $\mathrm{N} \mathrm{Engl}$ f Med 2000;342:1645-50.

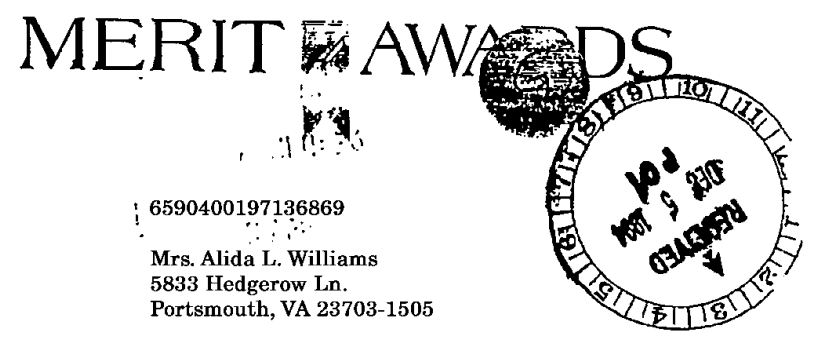

Dear Alida,

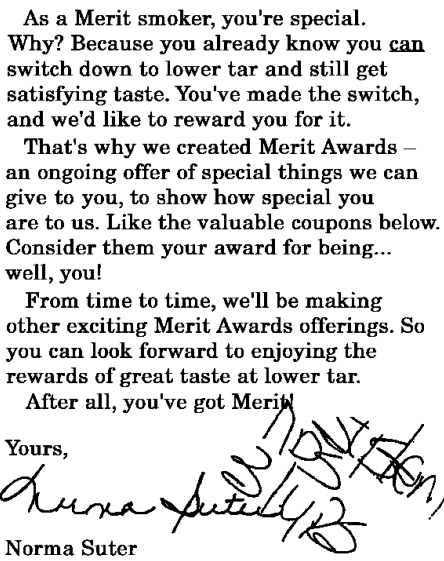

Norma Suter

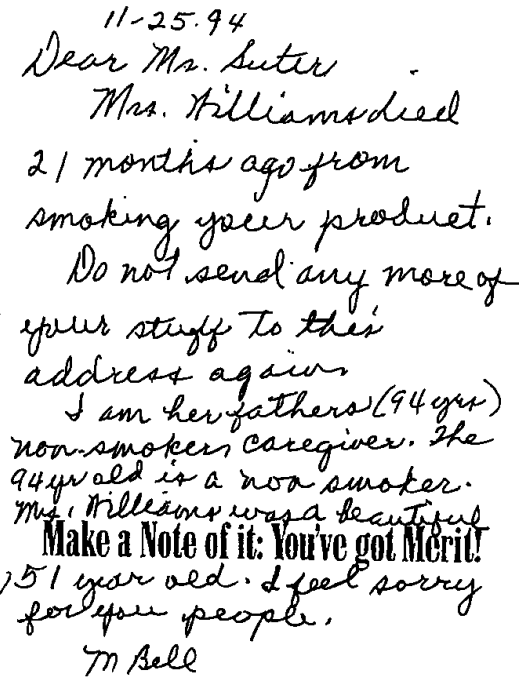

in Bell

P.S. To serve you better, we've included a survey. Make a note to fill it out as soon as you can - there's a special reward for it when you do!

70196-D3

Poignant correspondence from Philip Morris's collection of dirty linen (http:// www.pmdocs. com/getimg. asp?pgno $=0$ E'start $=0$ E $b o o l=2044935701$ E'docid $=2044935$ $701 \mathrm{~A} \mathcal{E}$ docnum $=1$ ). 